\title{
Model construction and application analysis under environment and resource constraints in China
}

\author{
Feiliang $\mathrm{Niu}^{1}$, and Yunzheng $\mathrm{Fu}^{2, *}$ \\ ${ }^{1}$ Statistics, College of Economics and Management, Kashgar University, 844006 Kashi, China \\ ${ }^{2}$ Economics, La Jolla Country Day School, 9490 Genesee Ave, La Jolla, San Diego,CA 92037, USA
}

\begin{abstract}
How to make sustainable development in the new era has been becoming the most important issue in China. This research explains why China could rapidly increase in the past, and how to fulfil a sustainable development under the resource and environmental constraints in the future by employing an endogenous growth model which includes "learning by doing" factors. Our model explains a learning mechanism called "learning by doing" and the knowledge reserve needed for the sustainable development. The empirical estimation results shows: under threats of environmental pollution and restrictions on natural resource depletion, an sustainable development is possible. Human capital use and technological advances crucially support the maintenance of sustainable growth, and the learning-by-doing effect increases the explanatory power of capital for knowledge production. The sustainable development awareness of consumers determines the economic growth quality. The explanation of the environmental pollution parameter could be extended to a policy simulation variable to measure the practical management level and the contamination controlling effect.

Keywords: Endogenous growth; Environment and resource constraints; Sustainable development.
\end{abstract}

\section{Introduction}

Since the implementation of the reform and opening-up policy in December 1978, China's economy has maintained a high growth rate of more than $8 \%$ for a long time, however, partly at the cost of environmental degradation and resource depletion. In the report of the 19th National Congress of the Communist Party of China (CPC) in 2017, the Chinese claimed that China must launch an economic transformation to fulfil a high-quality development. An economic transformation by changing its growth model, optimizing the economic structure, and transforming the forces which drive economic growth to make sustainable development. Since the notion of ecological conservation was put forward in the 16th national Congress of the Communist Party of China in November 2002, China has achieved notable progress in green development for the past 18 years (Zhang et al., 2020). Again, in the Fifth Plenum of the 19th Central Committee of the Communist Party of China in October 2020, the green

*Corresponding author: 1718750146@qq.com 
development requirement was to come up with a harmonious coexistence between human beings and nature. How to achieve sustainable development of the resource, environment, and economy while ensuring normal economic growth and a continuous increase in income is the most important issue to be studied during China's economic transition.

The purpose of this paper is to explain why China's economy could get a rapid increase in the past 40 years and how to fulfill a high-quality economic growth under the resource and environmental constraints in the future.

In the literature, there are several great traditional economic growth theories that take population, resources and knowledge into account. Those studies can be divided into two stages: the rise of the neoclassical growth theory model (Stiglitz,1974; Dasgupta and Heal, 1974; Hiraguchi,2016; Klarl, 2016; Boucekkine and Pintus et al., 2018; Gil and Afonso et al., 2018; Trimborn, 2018) and a new endogenous growth theory and mode that began in the late 1980s (Afonso O and Afonso AC, 2015; Fukuda, 2017; Michael, 2018; Chandril Bhattacharyya, Manash Ranjan Gupta,2021).

However, after the rapid economic development of the mid-20th century in the developed countries, there were various kinds of serious environmental hazards and energy crises occurring frequently, which drew more attention to the sustainable development issue related to environmental pollution and resource depletion. The earlier economists in the 1970s discussed the sustainability of economic growth by incorporating environmental or resource constraints into growth models, however, their studies have many inherent defects and insufficient explanations of technology or knowledge capital which remains in resource and environmental constraint models based on neoclassical growth theory. Since the 1980s, the development of endogenous growth theory has provided a broader perspective for research in related fields, and economists have also completed considerable amount of related research.

Increasingly more Chinese scholars have tried to use the endogenous growth model promoted by technology R\&D, and their models were established with environmental or resource constraints (Wu and Zhang et al., 2018; Mingyue Wang, etc,2020 ). However, they neglected the positive impact of learning-by-doing on economic growth. "Learning by doing", as a by-product of capital input, constantly generates the accumulation of production experience, which directly affects productivity.

From this perspective, we plan to establish an endogenous growth model incorporating the effect of human capital accumulation of "learning by doing. The environmental and resource constraints are considered simultaneously to determine the steady-state value to produce a more meaningful reference.

In addition, most scholars' research was either mainly based on theoretical model analysis without further empirical analysis, or only empirical analysis without theoretical model analysis, therefore, theory and demonstration were not combined. We used panel data from western Chinese provinces for empirical analysis and then examined the differences from the view of both theory and empirical evidence.

The structure of the paper is as follows: the first part is a literature review; The second part is the setting of the Model of Endogenous Growth Expansion; The third part is the data source explanation, as well as the econometric analysis of the relationship between energy use, environmental pollution and economic growth; The fourth part is the conclusion, countermeasures and future prospects.

\section{Modeling method}

In the process of economic transformation, the mass use of non-renewable resources placed constraints on long-term economic growth. Meantime, all kinds of environmental pollution from industrial production and human daily life placed another negative constraint on economic development. Under the dual constraints of natural resources and environmental 
pollution, we seek a solution to have sustainable growth by studying the theoretical model, realization mechanism, and countermeasures.

Based on Arrow's thought of "learning by doing" and Lucas' human capital accumulation, we assumed that in an economy, by establishing an extended three-sector endogenous growth model that includes the human capital sector, the end product sector, and the resource sector, environmental pollution and resource use were added as constraints into the new production function, and resource stock and environmental quality were introduced into the new utility function. For the convenience of analysis, we will suppose the population growth rate is 0 and the population is normalized to 1 . Then, the aggregate variable in the economy can be seen as the average. All variables in the following analysis are continuous-time functions (Zhang and Zou, 2007; Cabo and Mart'in-herr'an et al., 2016).

The simultaneous equations can be solved to obtain steady-state growth solutions:

$$
\begin{gathered}
g_{Y}=g_{K}=g_{C}=\gamma\left(\delta_{H}-\rho\right) /\left[1-(\alpha+\xi)-\frac{\eta(1-\sigma)}{1-\varphi}-\gamma(1-\sigma)+\frac{\sigma+\omega}{i(1+\omega)}\right] \\
g_{E}=\frac{1-\sigma}{1+\omega} g_{C} \\
g_{z}=-\frac{\sigma+\omega}{i(1+\omega)} g_{C} \\
g_{M}=g_{R}=\frac{1-\sigma}{1-\varphi} g_{C} \\
g_{H}=g_{H_{Y}}=(1-\sigma) g_{C}+\left(\delta_{H}-\rho\right)
\end{gathered}
$$

\section{Data}

Since the 2000s, China's energy consumption structure has undergone considerable changes, transforming the energy consumption structure to be dominated by coal and supplemented by clean energy. Due to the impact of the low-carbon policy and energy use technology progress, the proportion of coal consumption in China has dropped from a high $70 \%$ before 2000 to about $60 \%$ in 2018 . The proportion of primary electricity consumption provided by other energy sources such as wind power, nuclear power, water power, and solar energy rose steadily to more than $30 \%$, and the transformation of the energy consumption structure was consistent with the concept of sustainable development.

We chose total clean energy (except water power) consumption, coal consumption, and primary electricity consumption as explanatory variables to measure the level of economic growth with the total gross domestic product (GDP). According to the China statistical yearbook (the series data of total GDP from 1985 to 2018), total clean energy consumption, coal consumption, and the proportion of primary electricity in total energy consumption were collected. Coal consumption and primary electricity consumption were then calculated. The influence of price factors caused by inflation was smoothed out according to the GDP index. Among them, the unit of real GDP is 100 million RMB, taking the 1985 price level as the reference point. The units of clean energy consumption $\mathrm{R}$, oil, gas and coal consumption $\mathrm{C}$, and primary electricity consumption E, were converted into 10,000 tons of standard coal.

\section{Econometric analysis}

We have made comments on the relevant studies under the constraints of resources and environment, and put forward the ideas and mathematical methods that need to be improved. Next, we need to further verify them by using econometrics. 


\subsection{Analysis of the relationship between energy use and economic growth}

For the above time-variable data, the logarithmic method was adopted to eliminate heteroscedasticity without changing the data characteristics before the econometric analysis. The logarithms of the corresponding variables are $\operatorname{lnGDP}, \operatorname{lnC}$, and $\operatorname{lnE}$. For time-series data, stationarity is first tested, and a unit root test is usually conducted following the ADF(Augmented Dickey Fuller ) method. According to SC(Schwarz Criterion ) criteria, ADF test results are shown in Table1, where $\mathrm{C}$, $\mathrm{T}$, and $\mathrm{K}$ represent the absence of an intercept term, the time trend term, and the lag order, respectively. The variable name is preceded by the symbol $\Delta$ to denote the first difference term of the original variable. The test results show that the original sequences $(\operatorname{lnGDP}, \operatorname{lnR}, \ln \mathrm{E}$, and $\operatorname{lnC}$ ) are all unstable, but the first-order difference terms all pass the stationarity test at the level of 5\%, so $\ln G D P, \ln R, \ln E$, and $\ln C$ are all first-order single integrations, and the co-integration test can be applied.

Table 1. ADF Test Results of Various Energy Consumption and GDP.

\begin{tabular}{|c|c|c|c|c|c|}
\hline Variables & $(\mathbf{C}, \mathbf{T}, \mathbf{K})$ & $\begin{array}{l}\text { ADF Test } \\
\text { statistic }\end{array}$ & $\begin{array}{c}5 \% \\
\text { Critical } \\
\text { value }\end{array}$ & $\begin{array}{l}\text { Confidence } \\
\text { probability }\end{array}$ & $\begin{array}{l}\text { Confidence } \\
\text { probability }\end{array}$ \\
\hline lngdp & $(\mathrm{C}, \mathrm{T}, 2)$ & -1.466674 & -3.587527 & 0.8161 & instability \\
\hline$\Delta \operatorname{lngdp}$ & $(\mathrm{C}, 0,0)$ & -4.511057 & -2.971853 & 0.0013 & smooth \\
\hline $\ln R$ & $(\mathrm{C}, \mathrm{T}, 1)$ & -2.59664 & -3.580623 & 0.2843 & instability \\
\hline$\Delta \ln R$ & $(\mathrm{C}, 0,0)$ & -4.55441 & -2.971853 & 0.0012 & smooth \\
\hline $\ln \mathrm{E}$ & $(\mathrm{C}, \mathrm{T}, 0)$ & -1.868588 & -3.574244 & 0.6447 & instability \\
\hline$\Delta \ln \mathrm{E}$ & $(\mathrm{C}, 0,0)$ & -5.252799 & -2.971853 & 0.0002 & smooth \\
\hline $\ln C$ & $(\mathrm{C}, 0,0)$ & -1.467191 & -2.967767 & 0.5356 & instability \\
\hline$\Delta \operatorname{lnC}$ & $(\mathrm{C}, 0,0)$ & -4.190202 & -2.971853 & 0.0030 & smooth \\
\hline
\end{tabular}

\subsection{Analysis of the relationship between environmental pollution and economic growth}

The Granger causality test was further used for variables with co-integration relationships: lnsolid and lnagdp, and lnso 2 and lnagdp. The test results are shown in Table 2.

Table 2. Granger Causality Test Results of Each Pollution Variable and Per Capita GDP.

\begin{tabular}{|c|c|c|c|c|}
\hline Null hypothesis & Lag order & F statistic & $\begin{array}{c}\text { Confidence } \\
\text { probability }\end{array}$ & $\begin{array}{c}\text { Inspection } \\
\text { results }\end{array}$ \\
\hline $\begin{array}{c}\text { Inagdp is not the granger reason of } \\
\text { lnso2 }\end{array}$ & 1 & 0.87121 & 0.3612 & accept \\
\hline $\begin{array}{c}\text { Inso2 is not the granger reason of } \\
\text { lnagdp }\end{array}$ & 1 & 8.38558 & 0.0086 & reject \\
\hline $\begin{array}{c}\text { Inagdp is not the granger reason of } \\
\text { lnsolid }\end{array}$ & 1 & 1.94916 & 0.1773 & accept \\
\hline $\begin{array}{c}\text { Insolid is not the granger reason of } \\
\text { lnagdp }\end{array}$ & 1 & 5.33995 & 0.0311 & reject \\
\hline
\end{tabular}

The test results show that the per capita GDP is not the Granger cause of total sulfur dioxide emissions and industrial solid waste emissions. Whereas, both the total sulfur dioxide emissions and industrial solid waste emissions are the Granger cause of per capita GDP. This shows that China's economic growth is subject to sulfur dioxide and industrial solid waste emissions and can be coordinated accordingly to maintain sustainable economic and environmental development. 
According to the results of the co-integration test, for variables that do not exist in a cointegration relationship, such as lnwater and lnagdp as well as lncod and lnagdp, the dynamic mechanism between these two pairs' variables can be investigated by establishing a VAR model.

The basic equation form of the VAR model is:

$$
Y_{t}=A_{1} Y_{t-1}+A_{2} Y_{t-2}+\cdots+A_{P} Y_{t-P}+B X_{t}+E_{t}
$$

where $Y_{t}$ is an endogenous variable, $Y_{t-p}$ is an endogenous variable with p-order lag, $X_{t}$ is an exogenous variable, Et is a random error, variables $\mathrm{Y}$ and $\mathrm{X}$ are both variable vectors, $\left(A_{1}, A_{2}, \ldots, A_{P}\right)$ is a vector matrix to be estimated, and $\mathrm{p}$ is the lag order of the model. Before modeling the pollution emission variable and per capita GDP, it is necessary to test the stability of the VAR system and to determine the lag order of the VAR model.

The AR (Autoregressive) root estimation result shows that the reciprocal of all root modes of the VAR model is in the unit circle and the value is less than 1, so the model is stable(see Fig. 1).

Inverse Roots of AR Characteristic Polynomial

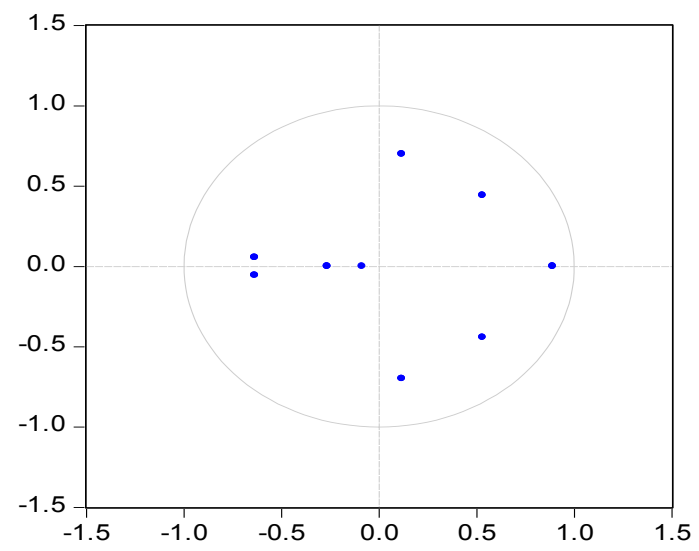

Fig. 1. AR root estimation.

According to the AIC (Akaike information criterion), LR (likelihood ratio test), and SC (Schwarz Criterion) principles, and combined with the data length, the lag order is 3 . We established vector autoregression models of stationary variables dlnagdp, dlnwater, and dlncod, whose matrix representation is:

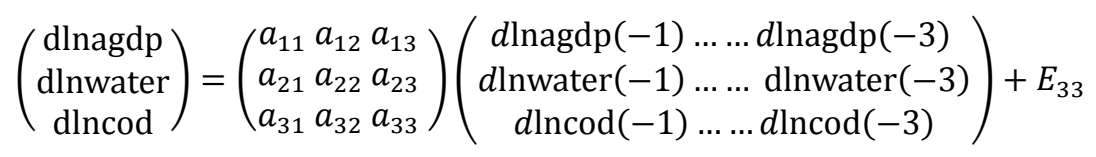

Where dlnagdp(-k) represents the k-order lag of dlnagdp and $E_{33}$ is the residual matrix. According to the matrix model, impulse response analysis and variance decomposition analysis can be applied to each variable. 
Response to Cholesky One S.D. Innovations ?2 S.E.

Response to Cholesky One S.D. Innovations ?2 S.E. Response of DLNAGDP to DLNCOD

Response of DLNCOD to DLNAGDP
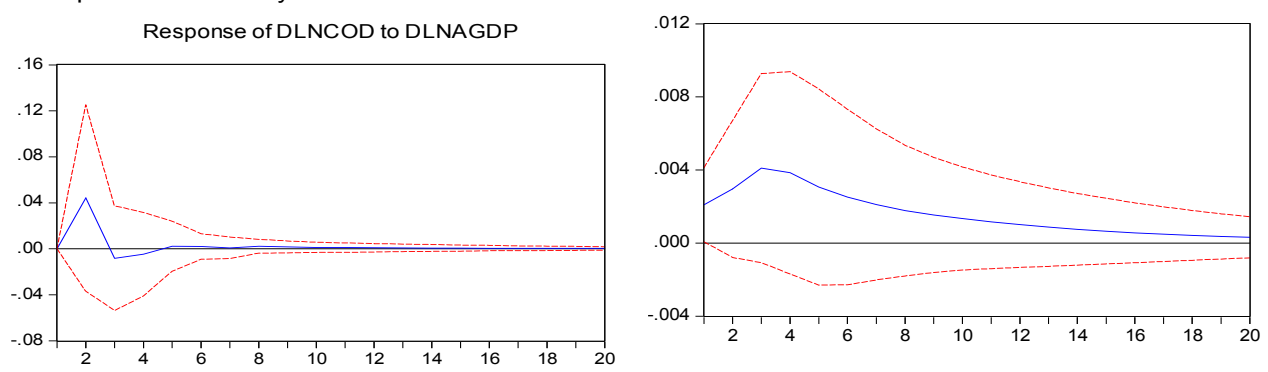

Response of DLNWATER to DLNAGDP
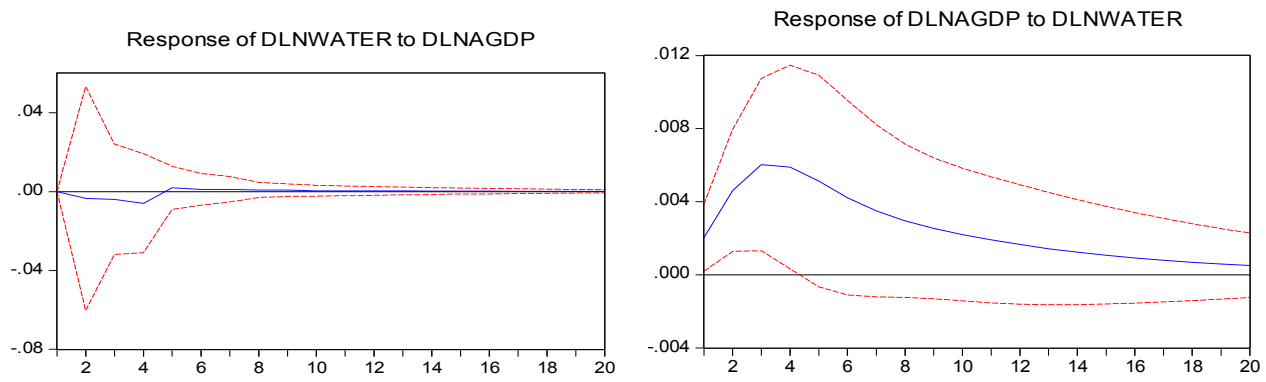

Fig. 2. Impulse Response of Pollution Variable and Economic Growth.

\section{Conclusion and Policy Implication}

After the theoretical discussion and supplement, this paper expands the new model under the constraint of resources and environment according to the new opinions, and uses the econometric model to verify, and obtains the corresponding conclusions, as well as the relevant issues that need to be further discussed.

\subsection{Conclusion}

China's primary electricity consumption and clean energy has increased substantially, and reached more than $30 \%$ of the total energy consumption in 2018 , while the proportion of coal consumption has further decreased. In terms of environmental treatment, the discharge of industrial solid waste has decreased significantly, the discharge of industrial wastewater has fluctuated considerably, the discharge of industrial waste gas has risen steadily on the whole, and the discharge of industrial sulfur dioxide has decreased slightly. From the perspective of governance, considering the cumulative effect of pollution over time and the considerable investment needed in the initial stage of environmental governance infrastructure implementation, the effectiveness of environmental governance still needs to be observed further.

\subsection{Policy implication}

Resource shortages and environmental pollution are common problems around the world. High-quality development is required to ensure the progress of human society in the present and future.

We need to vigorously promote ecological progress, effectively conserve resources, significantly reduce the intensity of energy resource consumption, and guide international 
cooperation on climate change. By those systematic changes, China can become an important contributor in global ecological progress.

Promoting Scientific and Technological progress, vigorously developing clean energy, and promoting the transformation and upgrade of the industrial structure.Improving the ecological compensation mechanism through the legal system. Vigorously promote a LowCarbon lifestyle.

\section{Acknowledgments}

This research was funded by the National Social Science Fund of China (12BJL086) and the National Social Science Fund of China (17BGL249).

\section{References}

1. Afonso O., Afonso A.C. Endogenous growth effects of environmental policies. Panoeconomicus 62, 607-629 (2015)

2. Chandril Bhattacharyya, Manash Ranjan Gupta. Unionised labour market, environment and endogenous growth. International Review of Economics \& Finance, Volume 72, 29$44(2021)$

3. Cabo F., Mart'in-herr'an G., Mart'in M.P. A note on the stability of fully endogenous growth with increasing returns and exhaustible resources. Macroeconomic Dynamics 20, 819-831 (2016)

4. Trimborn T. On the analysis of endogenous growth models with a balanced growth path. Journal of Mathematical Economics 79,40-50 (2018)

5. Wu T., Zhang N., Gui L., Wu W.J. Sustainable endogenous growth model of multiple regions: reconciling OR and economic perspectives. European Journal of Operational Research 269, 218-226 (2018)

6. Zhang H., Geng Z., Yin R.S., Zhang W. Regional differences and convergence tendency of green development competitiveness in China. Journal of Cleaner Production 254:119922 (2020) 